\title{
The definition of left bundle branch block influences the response to cardiac resynchronization therapy
}

Citation for published version (APA):

Caputo, M. L., van Stipdonk, A., Illner, A., D'Ambrosio, G., Regoli, F., Conte, G., Moccetti, T., Klersy, C., Prinzen, F. W., Vernooy, K., \& Auricchio, A. (2018). The definition of left bundle branch block influences the response to cardiac resynchronization therapy. International Journal of Cardiology, 269, 165-169. https://doi.org/10.1016/j.ijcard.2018.07.060

Document status and date:

Published: 15/10/2018

DOI:

10.1016/j.ijcard.2018.07.060

Document Version:

Publisher's PDF, also known as Version of record

Document license:

Taverne

Please check the document version of this publication:

- A submitted manuscript is the version of the article upon submission and before peer-review. There can be important differences between the submitted version and the official published version of record.

People interested in the research are advised to contact the author for the final version of the publication, or visit the DOI to the publisher's website.

- The final author version and the galley proof are versions of the publication after peer review.

- The final published version features the final layout of the paper including the volume, issue and page numbers.

Link to publication

\footnotetext{
General rights rights.

- You may freely distribute the URL identifying the publication in the public portal. please follow below link for the End User Agreement:

www.umlib.nl/taverne-license

Take down policy

If you believe that this document breaches copyright please contact us at:

repository@maastrichtuniversity.nl

providing details and we will investigate your claim.
}

Copyright and moral rights for the publications made accessible in the public portal are retained by the authors and/or other copyright owners and it is a condition of accessing publications that users recognise and abide by the legal requirements associated with these

- Users may download and print one copy of any publication from the public portal for the purpose of private study or research.

- You may not further distribute the material or use it for any profit-making activity or commercial gain

If the publication is distributed under the terms of Article $25 \mathrm{fa}$ of the Dutch Copyright Act, indicated by the "Taverne" license above, 


\title{
The definition of left bundle branch block influences the response to cardiac resynchronization therapy
}

\author{
Maria Luce Caputo $^{\mathrm{a}, *, 1,2}$, Antonius van Stipdonk ${ }^{\mathrm{b}, 1,2}$, Annekatrin Illner ${ }^{\mathrm{a}, 2}$, Gabriele D'Ambrosio ${ }^{\mathrm{a}, 2}$, \\ François Regoli ${ }^{\mathrm{a}, 2}$, Giulio Conte ${ }^{\mathrm{a}, 2}$, Tiziano Moccetti ${ }^{\mathrm{a}, 2}$, Catherine Klersy ${ }^{\mathrm{c}, 2}$, Frits W. Prinzen ${ }^{\mathrm{d}, 2}$, \\ Kevin Vernooy ${ }^{\mathrm{b}, 2}$, Angelo Auricchio ${ }^{\mathrm{a}, 2}$ \\ a Fondazione Cardiocentro Ticino, Lugano, Switzerland \\ b Department of Cardiology, Maastricht University Medical Center, Maastricht, the Netherlands \\ c Service of Biometry and Clinical Epidemiology, Fondazione IRCCS Policlinico San Matteo, Pavia, Italy \\ d Department of Physiology, Cardiovascular Research Institute Maastricht (CARIM), Maastricht University, Maastricht, the Netherlands
}

\section{A R T I C L E I N F O}

\section{Article history:}

Received 17 April 2018

Received in revised form 24 June 2018

Accepted 11 July 2018

Available online 17 July 2018

\section{Keywords:}

Cardiac resynchronization therapy

Electrocardiology

Heart failure

Left bundle branch block

Response

\begin{abstract}
A B S T R A C T
Background: CRT has been proven to achieve most benefit in patients with left bundle branch block morphology (LBBB). However, ECG criteria to define LBBB significantly differ from each other. Objective of the study was to evaluate the impact of different ECG criteria for LBBB definition on survival, hospitalization for heart failure and reverse remodelling in patients who received cardiac resynchronization therapy (CRT).

Methods and results: Three-hundred-sixteen consecutive patients were included in the analysis. Six different classifications were assessed in baseline ECGs of patients who received a CRT device: a QRS duration of $\geq 150 \mathrm{~ms}$ and LBBB according to AHA/ACC/HRS, ESC 2006, ESC 2009, ESC 2013 and the classification proposed by Strauss and colleagues. In univariate analysis, the ESC 2009 and 2013 and the Strauss classifications were significantly associated with a reduction in cumulative probability for heart failure (HF) and mortality (HR $0.60,95 \%$ CI $0.42-0.86$, HR $0.61,95 \%$ CI $0.43-0.87$ and $\mathrm{HR} 0.57,95 \%$ CI $0.40-0.80$, respectively). In multivariate analysis, the association with the combined endpoint was confirmed only for ESC 2009 and 2013 classifications and for Strauss. Moreover, the cumulative probability of all-cause death and HF hospitalizations was higher in patients who were negative for all the 5 LBBB classifications.

Conclusions: This study shows that the strength of the association of LBBB to outcome in CRT depends on the ECG classifications used to define LBBB, the simplest criteria (ESC 2009 and 2013) providing the best association with clinical endpoints in CRT.
\end{abstract}

(c) 2018 Elsevier B.V. All rights reserved.

\section{Introduction}

Cardiac resynchronization therapy (CRT) improves symptoms, quality of life, and survival in patients with reduced left ventricular (LV) ejection fraction, heart failure symptoms, and prolonged QRS duration. The randomized clinical trials that lead to the initial widespread adoption of CRT used only QRS duration of $>120 \mathrm{~ms}$ as entry criteria [1-4]. Ever since, multiple sub-analyses of large randomized trials showed QRS morphology to be associated to the measured benefit by CRT [5]. Where the benefit in patients presenting left bundle branch

\footnotetext{
* Corresponding author at: Division of Cardiology, Cardiocentro Ticino, Via Tesserete 48, CH-6900 Lugano, Switzerland.

E-mail address: marialuce.caputo@cardiocentro.org (M.L. Caputo).

1 Authors contributed equally.

2 This author takes responsibility for all aspects of the reliability and freedom from bias of the data presented and their discussed interpretation.
}

block (LBBB) on baseline ECG was shown to be very robust [6,7], in non-LBBB patients the benefit is still controversial [6,7]. Moreover, the specific criteria used to classify LBBB are not indicated in clinical practice guidelines [7,8].

Currently, there are multiple ECG criteria for LBBB proposed by scientific organizations [6,9-11] and research groups [12]. Moreover, the European Society of Cardiology (ESC) has changed criteria for LBBB a few times over the last decade $[6,10,11]$. While initially these criteria were used to classify the conduction abnormality per se, the more recent ones implicitly assume that LBBB represents the most important substrate for CRT. The lack of uniformity of LBBB criteria and uncertainty about the differences in association with outcomes to CRT can contribute to the still remaining group of patients experiencing no benefit from CRT.

Therefore, we aimed to study in a population of patients implanted with a CRT: 1) the consistency of a CRT patient to be classified as having LBBB, and 2) the association of different LBBB criteria with both reverse remodelling and hospitalization for HF and all-cause death. 


\section{Methods}

2.1. Study population

All consecutive patients who received a CRT at two different European centres (Cardiocentro Ticino, Lugano, Switzerland and Maastricht University Medical Center, Maastricht, The Netherlands) since 2006 to 2016 were retrospectively analysed for the inclusion in the study. Patients were indicated to CRT according to European guidelines indications available at time of CRT implantation. All patients underwent implantation of a CRT system, with or without implantable cardioverter-defibrillator capabilities based upon clinical decision and patient decision. Exclusion criteria were unavailable or poor quality baseline ECG, baseline right ventricular pacing, incomplete follow up data and biventricular pacing inadequate after implantation $(\leq 95 \%)$. The study protocol was approved by the locally appointed ethics committee and complied with the Declaration of Helsinki. Written informed consent has been obtained from all the subjects (or their legally authorized representative).

\subsection{ECG acquisition and analysis}

Standard supine 12 lead ECGs (filter range, 0.15 to $100 \mathrm{~Hz}$; AC filter, $60 \mathrm{~Hz}, 25 \mathrm{~mm} / \mathrm{s}$ speed, $1 \mathrm{~mm} / \mathrm{mV}$ ) were obtained at baseline and before discharge. In a blinded manner, one experienced reader interpreted QRS morphology based on morphological features of the five different ECG criteria. LBBB definitions used were the ones recommended by the AHA/ACC/HRS [9], the ones suggested by the ESC in 2006 [10] and 2009 [11] textbooks and the 2013 ESC guidelines [6], and finally the ECG definition proposed by Strauss et al. [12]; the criteria are summarized in Table 1. Notching in the QRS complex and slurring were defined according to Almer et al. [13] Notching was defined as a sudden change, within a slope (waveform), in direction $\geq 90^{\circ}$; slurring was defined as sudden change in the slope of a waveform with a change in direction $0^{\circ}-90^{\circ}$. QRS duration was always automatically measured by using ECG machine of two different vendors (Schiller CARDIOVIT CS-200 Excellence, Doral, FL, USA and ELI 350, Mortara Instrument, Inc. Milwaukee, WI, USA). In order to qualify for LBBB according to a specific definition, the ECG should comply with all required criteria for that definition.

\subsection{Echocardiographic measurements}

Echocardiographic evaluation was performed at baseline and at 6 months after device implantation. Images were acquired in the left lateral decubitus position with a commercially available system (GE Healthcare, Horten, Norway) with a 3.5-MHz transducer at a depth of $16 \mathrm{~cm}$ in conventional parasternal and apical views. LV end-systolic volume (LVESV) and end-diastolic volume (LVEDV) were measured at the apical 2- and 4chamber views; LV Ejection Fraction (LVEF) was calculated with the use of the biplane Simpson method. Reverse remodelling was defined as a reduction of LVESV of at least $15 \%$ assessed at 6 months after CRT implantation compared to baseline.

\subsection{Follow up}

Clinical follow-up of patients consisted of physical examination, ECG and echocardiogram performed at least every 6 months. Follow-up of the device was performed at 1 and 3 months after CRT implantation and every 6 months thereafter. Data on hospitalization for acute heart failure were systematically collected. The diagnosis of heart failure required signs and symptoms consistent with congestive heart failure that was responsive to intravenous decongestive therapy.

\subsection{Statistical analysis}

Continuous data are presented as median and 25th-75th percentiles (IQR) and categorical data as counts and percentages. They were compared between groups dichotomic with the Mann Whitney $U$ test and the Fisher exact test, respectively. Each patient's ECG was classified as LBBB or not according to the five classification methods described above. Therefore, each patient could have from 0 to 5 LBBB criteria satisfied. Comparisons according to the number of LBBB positive classification per patient used the Kruskal-Wallis test for continuous variables and the Fisher exact test for categorical variables. The test for trend was also applied. Significance was set at 0.003 for pairwise post-hoc comparisons.

The association of LBBB and reverse remodelling measured as a reduction of $15 \%$ of the LVESV at 6 months was assessed with a logistic model. Odds ratios (OR) and 95\% confidence intervals $(95 \% \mathrm{CI}$ ) were computed. Median follow-up (IQR) was computed with the inverse Kaplan Meier method. Event rates per 100 person year and 95\%Cl were computed.

Event-free survival was estimated by Kaplan-Meier method and compared with the logrank test. Hazard ratios (HR) and 95\%CI were calculated with a Cox model. The proportional hazard assumption was satisfied in all cases. Endpoints for these analyses were hospitalization for heart failure, death and the combined endpoint. For both modeling procedures, both univariable and multivariable models with adjustment for a priori selected clinical confounders were fitted. We computed the Harrell's c concordance statistic for all Cox models including in turn each LBBB classification (the higher the Harrell's c, the better model discrimination); we informally compared classifications by ranking the Harrell's c.

Statistical analyses were conducted using the Stata 15.1 software (Stata Corporation, College Station, TX, USA). A 2-sided $p$-value $<0.05$ was considered statistically significant.

\section{Results}

Since January 2006 to December 2016, 498 patients received a CRT at the two participating institutions. Of them, 45 patients were excluded because of poor quality of baseline ECG, 25 patients for biventricular pacing $<95 \%$ despite reprogramming, 15 patients because of baseline paced QRS without intrinsic rhythm and 97 patients were excluded due to incomplete follow up data. Three-hundred sixteen patients were finally included in the analysis (Lugano n: 156; Maastricht n: 160). Demographic characteristics of the study cohort are summarized in Table 2. The frequency of LBBB strongly depended on the ECG classification used, the proportion of patients meeting LBBB definitions ranging from 29\% (AHA) to 61\% (Strauss). One-hundred ninety-eight patients (63\%) had a LBBB according to at least one definition; of these, 33\% were positive for all five ECG classifications. As illustrated in the Table included in the Supplemental material, overlap among the LBBB classifications is present.

\subsection{QRS morphology and reverse remodelling}

One-hundred seventy-six patients (55\%) out of the 316 patients had $a \geq 15 \%$ reduction of baseline LVESV at 6 -month follow up. The proportion of patients with reverse remodelling varied according to different LBBB definitions and QRS duration (Fig. 1 - Supplemental material). Among all considered LBBB definitions, the ESC definitions showed the strongest association with reverse remodelling. When adjusted for confounding factors (age, gender, renal impairment, anti-remodelling therapy), the association with reverse remodelling was significant only for ESC 2009 and ESC 2013 definitions (OR 8.8, 95\% CI 1.3-56.5, p 0.01 and OR 8.7, 95\% CI 1.4-56.4, p 0.01, respectively).

\subsection{QRS morphology and heart failure hospitalization}

During a median follow up time of 55 months (IQR 25-79 months), 104 patients (33\%) were admitted to the hospital for acute heart failure after CRT implantation. The cumulative probability of hospitalization for

Table 1

ECG criteria to define Left bundle branch block.

\begin{tabular}{|c|c|c|c|c|c|}
\hline & AHA/ACC/HRS (2009) & ESC 2006 & ESC 2009 & ESC 2013 & Strauss (2011) \\
\hline QRS duration & $\geq 120 \mathrm{~ms}$ & $\geq 120 \mathrm{~ms}$ & $\geq 120 \mathrm{~ms}$ & $\geq 120 \mathrm{~ms}$ & $\mathrm{M}: \geq 140 \mathrm{~ms}, \mathrm{~F}: \geq 130 \mathrm{~ms}$ \\
\hline QS or rS pattern & - & V1 & V1, V2 & V1 & $\mathrm{V} 1, \mathrm{~V} 2$ \\
\hline QS pattern & - & aVR & - & - & - \\
\hline Positive T-wave/QRS concordance & Yes & V1 and aVR & - & - & - \\
\hline Delayed ID-time ( $\geq 60 \mathrm{~ms})$ & V5, V6 & I and V6 & - & - & - \\
\hline Discordant T-waves & Usually & Usually & - & - & - \\
\hline Notch/slurred R-wave & I, aVL, V5,V6 & - & I, aVL, V5, V6 & I, aVL, V5, V6 & I, aVL, V1, V2, V5, V6 \\
\hline Negative T-wave in leads with upright QRS & Yes & - & I, aVL, V5, V6 & - & - \\
\hline Absent Q-wave & I, V5, V6 & - & I, aVL, V5, V6 & V5, V6 & - \\
\hline
\end{tabular}

ID: intrinsicoid deflection. 
Table 2

Demographic data, baseline clinical parameters of the 316 CRT patients included in the study.

\begin{tabular}{ll}
\hline Parameter & All patients $(n=316)$ \\
\hline Male gender, n (\%) & $230(73)$ \\
Age, years, median [IQR] & $71[62-77]$ \\
Ischemic etiology, n (\%) & $196(62)$ \\
Persistent atrial fibrillation, n (\%) & $56(16)$ \\
NYHA functional class II/III-IV, n (\%) & $129(41) / 164(52)$ \\
ECG parameters & \\
Heart rate, bpm, median [IQR], & $71[62-83]$ \\
QRS duration, ms, median, [IQR] & $156[140-170]$ \\
QRS $\geq 150$ ms, n (\%) & $198(63)$ \\
LBBB + by ESC criteria 2006, n (\%) & $106(33)$ \\
LBBB+ by ESC criteria 2009, n (\%) & $145(46)$ \\
LBBB+ by ESC criteria 2013, n (\%) & $148(47)$ \\
LBBB + by AHA/ACC/HRS, n (\%) & $92(29)$ \\
LBBB+ by Strauss et al., n (\%) & $194(61)$ \\
Medication, $\mathrm{n}(\%)$ & \\
Beta-blocker & $297(94)$ \\
ACE inhibitor or ARB & $278(88)$ \\
MRAs & $230(73)$ \\
Diuretics & $230(73)$ \\
Amiodarone & $38(12)$ \\
Echocardiographic parameters, median [IQR] & \\
LV ejection fraction, \% & $28[23-33]$ \\
LV end-diastolic volume, ml & $184[147-227]$ \\
LV end-systolic volume, ml & $133[101-172]$ \\
\hline
\end{tabular}

NYHA: New York Heart Association; LBBB+: Left bundle branch block positive according to the indicated classification; ACE: Angiotensin-converting-enzyme; MRAs: mineralocorticoid receptor antagonists; ARB: Angiotensin receptor blocker; LV: left ventricle.

heart failure during follow-up was on average lower among patients with LBBB than in those without LBBB. However, it was statistically significant only when applying the ESC 2009 (logrank test p 0.002, HR = $0.54,95 \%$ CI 0.34-0.85), the ESC 2013 (HR $=0.55,95 \%$ CI 0.36-0.82, p 0.003 ), the Strauss ( $\mathrm{HR}=0.55,95 \% \mathrm{CI} 0.38-0.82, \mathrm{p} 0.002)$ and the AHA definitions ( $\mathrm{HR}=0.60,95 \% \mathrm{CI} 0.37-0.97$, p 0.03), respectively.

\subsection{QRS morphology and mortality}

During the follow-up, 81 patients (25\%) died. Survival rate between LBBB and non-LBBB patients differed irrespective of the definitions. However, no significant difference in term of survival prediction was observed among different ECG definitions.

The cumulative probability of the combined event (mortality and hospitalization for heart failure) was significantly reduced (Fig. 1) in patients with LBBB according to ESC 2009, ESC 2013 and Strauss definitions. When adjusted for confounding factors, the probability of the combined event was significantly lower only for patients having LBBB according to ESC 2009 and ESC 2013 definitions (HR 0.75, 95\% CI 0.68-0.83, p 0.004 and HR 0.74, 95\% CI 0.66-0.83, p 0.006, respectively, Fig. 1) and for Strauss definition (HR 0.50, 95\% CI 0.17-1.49, p 0.001, Fig. 1). Notably, cumulative probability of combined event was significantly higher in those patients who did not fulfil any of the five LBBB classifications $(N=118)$, respect to those who were positive for one or more LBBB classifications (Fig. 2). As shown in Fig. 2 of Supplemental material, ESC 2103 and Strauss classifications ranked highest by the Harrell's c statistic of the Cox models assessing the combined endpoint of HF hospitalization and mortality. LBBB classifications based on QRS and AHA ranked lowest. The ESC 2013 and AHA classifications consistently ranked highest and lowest, respectively, for HF hospitalization and mortality.

\section{Discussion}

To the best of our knowledge, this is the first study that systematically investigated how the ECG definition of LBBB is related to the clinical benefit of CRT. We demonstrated that the criteria adopted to define the LBBB on ECG differ in their classification of patients, and are not equally associated to the clinical benefit of CRT with regards to the proportion of patients showing reverse remodelling, heart failure hospitalization and survival rate.

Strikingly, the "simpler" LBBB definitions, as proposed by the more recent ESC criteria, provided an equal or better differentiation between CRT responders and non-responders as compared to so-called "stricter" LBBB criteria. The highly selective AHA criteria resulted in high percentages of CRT response in both LBBB-positive and LBBB-negative patients. The elegancy of these results is that the use of simple ECG criteria (e.g. notching, slurring in precordial leads) provides good selection for CRT device implantation. By comparing the components of these three classifications to the components of the other definitions, it seems that QS or rS pattern in V1, notching/slurring in V5, V6 and absence of $\mathrm{Q}$ in V5, V6 are the most important criteria, whereas intrinsicoid time and $\mathrm{T}$ wave morphology seem to contribute less to the prediction of clinical response.

\subsection{LBBB definition influences CRT outcome prediction}

The data from the present study confirm findings from previous studies that the extent of LV volumetric changes (i.e., reverse remodelling), and clinical outcomes are affected by baseline ECG characteristics $[14,15]$. Sweeney et al. demonstrated that an ECG pattern representing complete LBBB is a strong predictor of response to CRT [16]. This observation was consistent with results from the COMPANION [17], MADIT-CRT [2] and RAFT [3] studies. However, our findings significantly expand these findings, indicating that the definition of LBBB influences on the prediction of both the echocardiographic and clinical response to CRT. Among the herein studied ECG classifications, the ESC 2009 and 2013 definitions and the Strauss definition are the only ones that significantly stratify the probability of hospitalization for heart failure and the combined endpoint. These results are in partial agreement with other recent studies. For the first time, we showed that patients who did not fulfil any criterion of the herein considered ECG classification of LBBB, thus possibly being the "true non-LBBB" patients, had the worse prognosis. In contrast, by having at least 2 or more criteria of LBBB significantly reduced the event rate of mortality, hospitalizations for heart failure or both.

Tian et al. [18] found that LVEF increased significantly after CRT in 22 patients with a strict definition of LBBB, but not in 17 patients who had less than two notches. These data seem therefore to be in line with the present study, where all definitions that include QRS notching were predictive of better CRT response. Our data are in partial disagreement with Bertaglia et al. [19] who included 335 CRT patients. They found on average no significantly different response (echocardiographic change and time to cardiovascular hospitalization or death) between patients with "strict LBBB" vs. "traditional LBBB". However, in this study, only patients with LBBB according to AHA criteria were included and "strict LBBB" definition was obtained by applying the Strauss definition on top of the AHA definition. On the other hand, the results by Bertaglia et al. support our observation that CRT response can be predicted equally good by using less restrictive LBBB definitions, if they include QS or rS pattern in V1 and notches and no Q in lateral leads.

\subsection{Critical components of the LBBB definition}

As compared to the ESC 2009 criteria, the ESC 2013 definitions consider the absence of Q-wave in V5 and V6 as criterion of LBBB. Even if the presence of Q waves in leads I, V5, and V6 cannot exclude patients from a diagnosis of LBBB [11], this addition may be useful for predicting CRT response because such Q-wave may indicate the presence of a scar tissue in the lateral/postero-lateral wall, that likely limits the response to CRT.

Of note, in the present study $42 \%$ of patients missed a LBBB classification according to AHA due to lack of a discordant T-wave. In a subanalysis of MADIT-CRT, it was observed that LBBB patients with concordant $\mathrm{T}$ wave had a better outcome in terms of hospitalization 

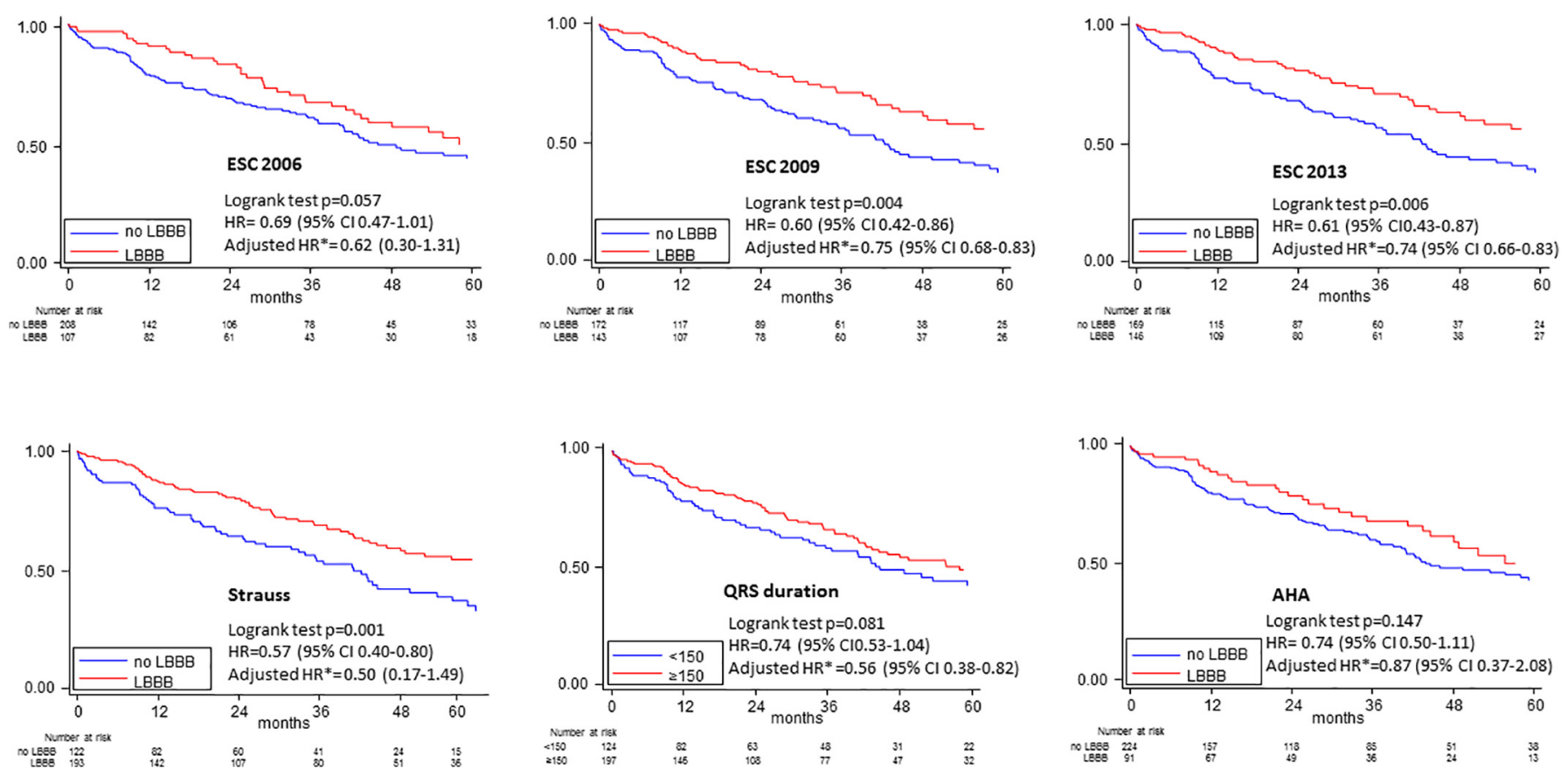

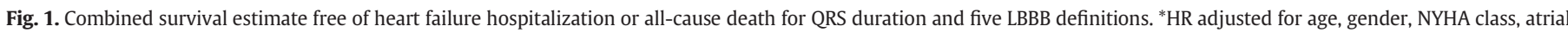
fibrillation, baseline end diastolic volume (EDV).

and survival, regardless of the treatment by CRT [20]. Therefore, the subgroup of non-LBBB patients according to AHA/ACC/HRS criteria is likely composed of a mix of "true" CRT non-responders and wellperforming complete LBBB patients. This may in part explain why in the present study there was a relatively small difference in long-term prognosis (heart failure hospitalization and survival rate) between patients qualified as LBBB and non-LBBB according to AHA/ACC/HRS. The present study shows that using QRS morphology, it can help identify patients that will probably benefit of CRT. However, the study also shows that the choice of the correct criteria is associated with the outcome to CRT. In this regard, the proper determination of notching and slurring is a key element, which may be user- and system-(filtering) dependent; furthermore, recent reports indicate large inter-observer and intra-observer variability in manual reading [21]. There is no standard definition of QRS notch and slur patterns in modern quantitative electrocardiology, likely because definitions are difficult to apply manually by clinicians since they rely on very small amplitude and duration measurements. From a conceptual point of view, in a recent patient-specific computer simulation study, Nguyen et al. showed that notching/slurring patterns in the precordial leads V1, V2, V5, and V6 and ID-time were affected by the position of the heart in the patients' chest and by appropriate positioning of electrodes on the chest [22]. These variations affected the LBBB/non-LBBB diagnosis, based on AHA/ ACC/HRS, ESC 2006 and Strauss definitions. In addition, measurement

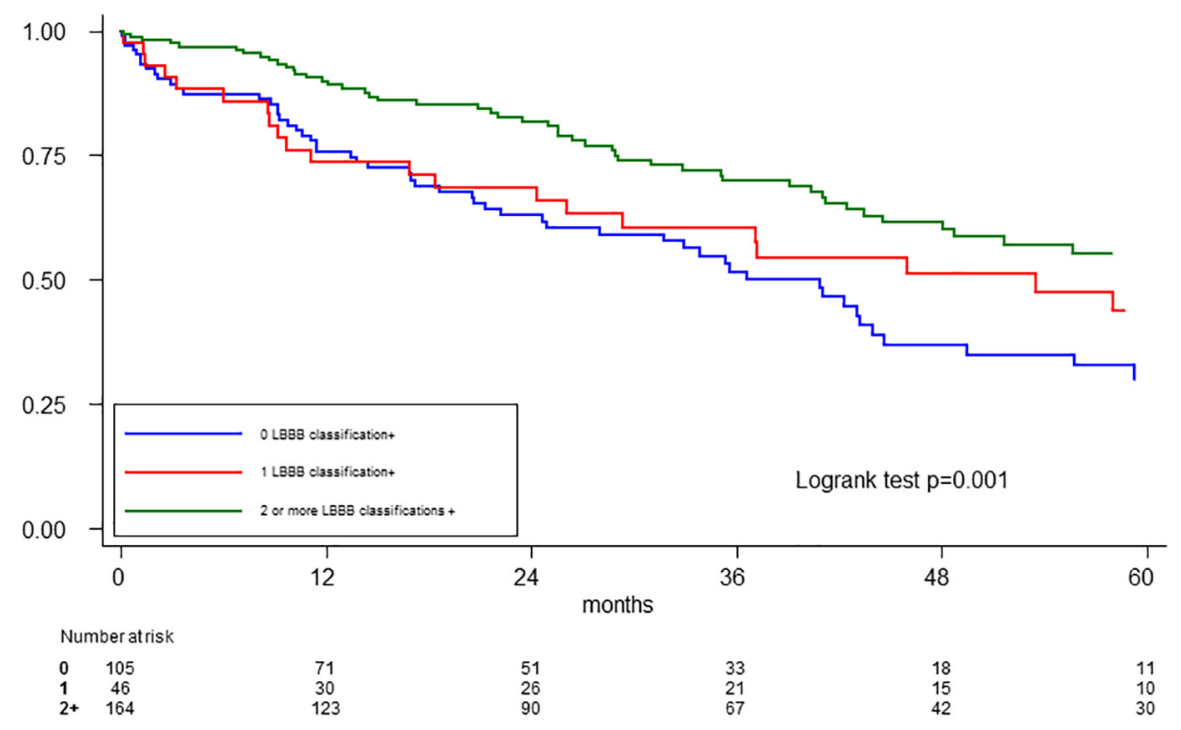

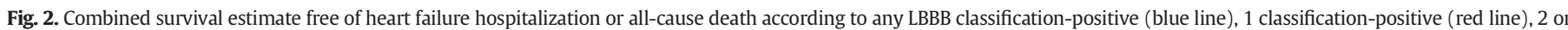
more classifications-positive. 
of QRS duration has its uncertainties [23]. The difference may exceed the level of $10-15 \mathrm{~ms}$, which might be considered clinically significant for qualifying a patient for CRT [24]. Therefore, it is imperative to develop a universally accepted standard on ECG classification for ventricular conduction disturbance, to request its implementation by all ECG vendors, and to mandatorily prescribe its use in future CRT studies and in clinical practice guidelines.

\subsection{Limitations}

This study has some limitations. The retrospective design implies that comparisons were only performed within the same patients, without a control group in which CRT was deactivated. Although quadripolar LV lead technology was clinically introduced around 2012; the proportion of patients who received a quadripolar LV lead was negligible $(<5 \%)$. Furthermore, none of the devices was capable of multipoint pacing. Functional capacity was assessed using NYHA class only, which considering the retrospective design of the study could be considered acceptable.

\section{Conclusions}

The ECG definitions adopted to define LBBB morphology have a significant influence on clinical outcome and reverse remodelling in patients who receive CRT. A consensus view needs to be established on how best to define QRS morphology and standardize the diagnostic criteria for LBBB, in order to optimize the selection of patients suitable for CRT.

Supplementary data to this article can be found online at https://doi. org/10.1016/j.ijcard.2018.07.060.

\section{References}

[1] A. Auricchio, C. Stellbrink, S. Sack, et al., Pacing Therapies in Congestive Heart Failure (PATH-CHF) Study Group, Long-term clinical effect of hemodynamically optimized cardiac resynchronization therapy in patients with heart failure and ventricular conduction delay, J. Am. Coll. Cardiol. 39 (2002) 2026-2033.

[2] A.J. Moss, W.J. Hall, D.S. Cannom, et al., MADIT-CRT Trial Investigators, Cardiacresynchronization therapy for the prevention of heart-failure events, N. Engl. J Med. 361 (14) (2009 Oct 1) 1329-1338.

[3] A.S. Tang, G.A. Wells, M. Talajic, et al., Resynchronization-Defibrillation for Ambulatory Heart Failure Trial Investigators, Cardiac-resynchronization therapy for mild-to-moderate heart failure, N. Engl. J. Med. 363 (25) (2010 Dec 16) 2385-2395.

[4] J.G. Cleland, J.C. Daubert, E. Erdmann, et al., Longer-term effects of cardiac resynchronization therapy on mortality in heart failure [the Cardiac REsynchronization-Heart Failure (CARE-HF) trial extension phase] cardiac resynchronization on mortality in the CARE-HF extension study, Eur. Heart J. 27 (2006) 1928-1932.

[5] K.C. Bilchick, S. Kamath, J.P. DiMarco, G.J. Stukenborg, Bundle-branch block morphology and other predictors of outcome after cardiac resynchronization therapy in medicare patients, Circulation 122 (2010) 2022-2030.

[6] M. Brignole, A. Auricchio, G. Baron-Esquivias, et al., 2013 ESC Guidelines on cardiac pacing and cardiac resynchronization therapy: the Task Force on cardiac pacing and resynchronization therapy of the European Society of Cardiology (ESC). Developed in collaboration with the European Heart Rhythm Association (EHRA), Eur. Heart J. 34 (2013) 2281-2329.

[7] C.M. Tracy, A.E. Epstein, D. Darbar, et al., American College of Cardiology Foundation; American Heart Association Task Force on Practice Guidelines; Heart Rhythm
Society, 2012 ACCF/AHA/HRS focused update of the 2008 guidelines for devicebased therapy of cardiac rhythm abnormalities: a report of the American College of Cardiology Foundation/American Heart Association Task Force on Practice Guidelines and the Heart Rhythm Society, Circulation 126 (2012) 1784-1800.

[8] J.J. McMurray, S. Adamopoulos, S.D. Anker, et al., ESC Committee for Practice Guidelines, ESC Guidelines for the diagnosis and treatment of acute and chronic heart failure 2012: The Task Force for the Diagnosis and Treatment of Acute and Chronic Heart Failure 2012 of the European Society of Cardiology. Developed in collaboration with the Heart Failure Association (HFA) of the ESC, Eur. Heart J. 33 (2012) 1787-1847.

[9] B. Surawicz, R. Childers, B.J. Deal, et al., AHA/ACCF/HRS recommendations for the standardization and interpretation of the electrocardiogram: part III: intraventricular conduction disturbances: a scientific statement from the American Heart Association Electrocardiography and Arrhythmias Committee, Council on Clinical Cardiology; the American College of Cardiology Foundation; and the Heart Rhythm Society. Endorsed by the International Society for Computerized Electrocardiology, J. Am. Coll. Cardiol. 53 (2009) 976-981.

[10] A. Bayés De Luna, V.N. Batchvarov, M. Malik, Chapter 1: the morphology of the electrocardiogram, in: A.J. Camm (Ed.), The ESC Textbook of Cardiovascular Medicine, Blackwell Publishing 2006, pp. 1-35.

[11] F.G. Cosío, J. Palacios, A. Pastor, A. Núñez, Chapter 2 the electrocardiogram, in: A.J. Camm (Ed.), The ESC Textbook of Cardiovascular Medicine (2 Ed.), Oxford University Press 2009, pp. 29-83.

[12] D.G. Strauss, R.H. Selvester, G.S. Wagner, Defining left bundle branch block in the era of cardiac resynchronization therapy, Am. J. Cardiol. 107 (2011) 927-934.

[13] J. Almer, R. Zusterzeel, D.G. Strauss, et al., Prevalence of manual Strauss LBBB criteria in patients diagnosed with the automated Glasgow LBBB criteria, J. Electrocardiol. 48 (2015) 558-564.

[14] C. Linde, W.T. Abraham, M.R. Gold, M. St. John Sutton, S. Ghio, C. Daubert, REVERSE (REsynchronization reVErses Remodeling in Systolic left vEntricular dysfunction) Study Group, Randomized trial of cardiac resynchronization in mildly symptomatic heart failure patients with left ventricular dysfunction and previous heart failure symptoms, J. Am. Coll. Cardiol. 52 (2008) 1834-1843.

[15] I. Sipahi, J.C. Chou, M. Hyden, D.Y. Rowland, D.I. Simon, J.C. Fang, Effect of QRS morphology on clinical event reduction with cardiac resynchronization therapy: meta-analysis of randomized controlled trials, Am. Heart J. 163 (2012) 260-267.

[16] M.O. Sweeney, R.J. van Bommel, M.J. Schalij, C.J. Borleffs, A.S. Hellkamp, J.J. Bax, Analysis of ventricular activation using surface electrocardiography to predict left ventricular reverse volumetric remodeling during cardiac resynchronization therapy, Circulation 121 (2010) 626-634.

[17] M.R. Bristow, L.A. Saxon, J. Boehmer, et al., Cardiac-resynchronization therapy with or without an implantable defibrillator in advanced chronic heart failure (COMPANION) investigators, N. Engl. J. Med. 350 (2004) 2140-2150.

[18] Y. Tian, P. Zhang, X. Li, et al., True complete left bundle branch block morphology strongly predicts good response to cardiac resynchronization therapy, Europace 15 (2013) 1499-1506.

[19] E. Bertaglia, F. Migliore, A. Baritussio, et al., Stricter criteria for left bundle branch block diagnosis do not improve response to CRT, Pacing Clin. Electrophysiol. 40 (2017) $850-856$.

[20] L. Padeletti, A. Aimo, B. Vishenvsky, et al., The prognostic benefit of cardiac resynchronization therapy is greater in concordant vs. discordant left bundle branch block in the Multicenter Automatic Defibrillator Implantation Trial-Cardiac Resynchronization Therapy (MADIT-CRT), Europace 20 (2018) 794-800.

[21] J.G. Cleland, W.T. Abraham, C. Linde, et al., An individual patient meta-analysis of five randomized trials assessing the effects of cardiac resynchronization therapy on morbidity and mortality in patients with symptomatic heart failure, Eur. Heart J. 34 (2013) 3547-3556.

[22] D.R. Tomlinson, Y. Bashir, T.R. Betts, K. Rajappan, Accuracy of manual QRS duration assessment: its importance in patient selection for cardiac resynchronization and implantable cardioverter defibrillator therapy, Europace 11 (2009) 638-642.

[23] U.C. Nguyên, M. Potse, F. Regoli, et al., An in-silico analysis of the effect of heart position and orientation on the ECG morphology and vectorcardiogram parameters in patients with heart failure and intraventricular conduction defects, J. Electrocardiol. 48 (2015) 617-625.

[24] V. Vancura, D. Wichterle, I. Ulc, et al., The variability of automated QRS duration measurement, Europace 19 (2017) 636-643. 